\title{
CONTINUOUS PROFESSIONAL DEVELOPMENT: TEACHERS' VOICES
}

\author{
Suharyadi \\ Universitas Negeri Malang \\ Suharyadi.fs@um.ac.id \\ Gunadi Harry Sulistyo \\ Universitas Negeri Malang \\ Gunadi.hs@gmail.com

\section{Sri Rachmajanti} \\ Universitas Negeri Malang \\ loekisr@gmail.com
}

\begin{abstract}
Being professional English teachers requires knowledge and competences that should be continuously nurtured to sustain their expertise, and one of the programs in Indonesia is the so-called Continuous Professional Development as officially declared by the Indonesian government in 2012 . Certified teachers generally undergo either short- or long-term training experiences to update their teaching knowledge and skills. However, little empirical evidence has been conducted to examine the sustainability of such training practices on the teachers' professionalism. Henceforth, this study is aimed at investigating how such English teacher professional development training practices have been carried out and what teachers expect from such training. To that end, a survey is conducted involving a number of teachers drawn randomly from different six provinces, i.e. East Java, West Java, Lampung, East Borneo, South Sumatra, and East Papua throughout Indonesia. Descriptive statistical analyses are exerted to analyze the data collected. The findings suggest that a more down-to-earth reflective training as continuous professional development is in compelling need.
\end{abstract}

Keywords: Continuous Professional Development, Teachers' Voices, Certified Teachers, Training Experiences

\section{INTRODUCTION}

A teacher is an integral part of educational organization at schools, and therefore, there should be a conducive learning atmosphere for her/him to develop professionally and continuously which enables them to face vast changes of demands in the global or modern life. It has been empirically verified by Guskey (2003) that teacher professional development (PD) shows a positive impact on both teachers' credentials and students' achievements. Moreover, PD is considered indispensable for teachers inasmuch as higher education institutions are in general not able to extend an extensive range of learning experiences for them after their graduation. It takes experienced teachers years of experience to be effective in the classroom and learn continuously to face new challenges and demands in education, let alone new teachers (Mizell, 2010).

Concerning effective teaching, Darling-Hammond (2000: 2-7) opines that teachers should possess the following competence: verbal ability, content knowledge, education coursework, teacher certification, and teacher experience. Verbal ability is the ability to communicate content knowledge through words and actions to their students that brings a positive effect on student achievement. In term of content knowledge, teachers with a subject matter-related major are more likely to be engaged in professional development, and subsequently, tailor what they learn into instruction. Education coursework deals with the provision of a balanced portion of subject matter coursework and pedagogical work, while teacher certification focuses more on the relevance of teachers' licenses to their field of study. Finally, teacher experience refers to the length of time devoted to instruction. Sanders and Rivers (1996:4-5) in their study discovered that in the first seven years of teaching teachers' effectiveness increased, but inclining to be flat by around year ten.

Henceforth, teachers' competences need to be upgraded periodically/continuously to nurture their professionalism. Concerning professional development (PD), Davidson, Dunlop, Soriano, Kennedy, \&Phillips (2012) and the Indonesian laws through The Teachers and Lecturers Act No.14/2005 (2005, 2007) and the Ministry Education and Culture (2012) have categorized PD into several types, i.e., (1) promoting Personally-Initiated Learning (PIL) which covers activities such as reading English-related materials (including research journals, printed or electronic), taking online courses, sharing ideas with 
colleagues, applying innovative teaching strategies, conducting collaborative projects with teachers from other countries, and conducting research; (2) attending Organized Professional Development (OPD) such as workshops, seminars, and trainings on English education and pedagogy , and joining short summer courses; (3) publishing Innovative Work (IW) which includes joining and winning some international writing competitions, writing instructional design to facilitate teacher training, producing electronic instructional materials; (4) upgrading into Qualified Professional Teachers (QPT) which include having official professional certification, having computer certificates (Microsoft, for example), having post graduate degree, master's or doctorate, as well as being a certified master teacher; and (5) managing More Advanced Roles (MAR), for instance, being a 2013 regional, provincial or national curriculum instructor, or becoming a teacher assessor at school. In brief, it goes without saying that the aforementioned efforts of PD are indispensable for English teachers in Indonesia as well.

As has been postulated in the law for Indonesian teachers (Ministry of Education and Culture,2005; 2007), a teacher is legally claimed as a dignified profession because s/he is in charge of preparing and producing smart and competitive human resources as reflection of the 2025 vision of education. As a consequence, $s /$ he is obliged to develop her/his profession continuously to face internal and external changes and uncertainties in modern era which require adaption and adjustment. One of the efforts to do so is likely by creating a learning atmosphere or community in which s/he can always upgrade her/his personal, social, pedagogical and professional competences through many ways. The two latter attributes can be manifested and evaluated by the teachers' profile through formal performance evaluation supported by self-evaluation to sustain their professionalism.

In relation to this, studies in Indonesia have been conducted by Utami, Saukah, Cahyono, \& Rachmajanti (2017) and Amalia (2017). It was discovered in the first qualitative research in a case study design that (1) English teachers' continuous professional development (CPD) involvement levels are determined by various indicators such as the breadth of CPD participation, the frequencies of participation, and the professional enthusiasm incorporating motivations and attitudes toward professional development. All in all, to evaluate teachers' performance in terms of CPD involvement levels, it is mandatory to consider professional enthusiasm instead of merely counting the frequency of their PD participations. (2) Affective factors such as motivation and attitude play critical roles in the quality of one's learning; and (3) out of the six respondents with working experiences ranging from 12 up to 27 years, only $50 \%$ (three respondents) were motivated (showing enthusiasm) to implement what they acquired from professional trainings in the learning process in class with their students, that is they did their best to make use of various learning strategies and provide interesting learning materials.

On the other hand, the second qualitative research with the same design examined two fresh bachelor graduates as respondents (one high and one low achievers) joining a government program to teach English in underprivileged areas in which before doing the teaching practice there, they had to join pre-service training for about several months. It was empirically verified that (1) the government program successfully accomplished one of its objectives that is to improve pre-service teachers' pedagogical competences to be prospective professional teachers, particularly for the low achiever teacher after one-year teaching practice in the underprivileged areas; (2) this teacher succeeded in making more advancement of pedagogical competence criteria than the high achiever who, in fact, prior to the training was more pedagogically competent. This finding was endorsed by Gnanaguru and Kumar (2007) stating that a high achiever teacher tends to show more positive attitude toward teaching performance than a low achiever teacher.

In a prior monitoring and mentoring program in which the researchers are involved, it is revealed that not more than $40 \%$ of teachers who attended short professional trainings on the implementation of Curriculum 2013 implement what they learn in the training for several reasons. Some of the reasons are : they did not have sufficient time to finish instructional materials in one semester if student-oriented learning process was put into practice; there were other non-academic matters that should be managed; they preferred the conventional way of teaching which is more teacher-centered; and there were misconceptions of cooperative and collaborative group work. Not only did they attempt to improve the instructional process, but they were also reluctant to upgrade themselves by conducting empirical studies in their own class and writing the results of the study for publication. So far, there have been a few researches investigating the impact of pedagogical and professional training practices on teachers' professional development. Therefore, this study is aimed at investigating the implementation of English teachers' professional training practices and their impact on their future professional development.

\section{RESEARCH METHOD}

This research is a descriptive study which adopts a survey design through the administration of a questionnaire and an observation sheet to collect data from the samples. The samples are conveniently drawn to represent a population to which the findings of the result of data analysis can be generalized (Gall, Gall, \& Borg, 2007). The questionnaire was distributed to 214 lower secondary English 
teachers selected randomly from 7 (seven) different provinces, i.e., East Java, West Java, Lampung, East Borneo, North Sumatra, South Sumatra, and East Papua. The English teachers as the subjects of the study are mostly civil servants with at least two-year teaching experience and have been teaching English at schools in remote areas as well as in the cities. Most of them (98\%) have an English Language Teaching (ELT) background and the rest have non-ELT background.

The instruments used for data collection in this study are questionnaire and observation sheets. The questionnaire is used to collect the main data which consist of 13 (thirteen) variables. Each variable is elaborated into 2-4 descriptors, divided into 31 items. The variables includes the kind and length of teacher training attended, the trainers' qualifications and their preparation, the training's significance, training materials, the benefits and drawbacks of the training, teachers' expectation and empowerment, the use of information technology in instructional process, the application and dissemination of training results through scientific writing, the significance of action research, and the journal publication. The observation sheets were used to collect supporting data. The observation sheets consist of three main variables namely: pre-activities, whilst activities and post activities. Each of them was elaborated into descriptors consisting three or four items. Having collected the data, the researchers utilized descriptive statistical analyses to examine the data collected using frequency count.

\section{FINDINGS}

Based on the result of descriptive statistical analyses, it was discovered that firstly, in terms of their teaching experiences, the respondents have different lengths of cumulative teaching experiences as shown in Table 1.

Table1. Years of Teaching Experiences
\begin{tabular}{|c|c|c|c|c|}
\hline Years & f & $\%$ & Valid \% & Cumulative \\
\hline$<5$ & 73 & 34.6 & 34.6 & 34.6 \\
\hline $5-10$ & 64 & 30.3 & 30.3 & 64.9 \\
\hline $11-15$ & 40 & 19.0 & 19.0 & 83.9 \\
\hline $16-20$ & 18 & 8.5 & 8.5 & 92.4 \\
\hline $21-25$ & 15 & 7.1 & 7.1 & 99.5 \\
\hline $26-30$ & 1 & .5 & .5 & 100.0 \\
\hline
\end{tabular}

$\mathrm{N}=211$

As shown in Table 1, the majority of the respondents (64.9\%) have less than 10 year teaching experiences. Only, a few (8.5\%) have more than 10 years teaching experiences.

The number of respondents who are certified and those who are not yet certified is slightly different, figuring at $51.2 \%$ and $48.8 \%$ respectively as shown in Table 2.

Table 2. Teacher Certification Status

\begin{tabular}{|c|c|c|c|c|}
\hline Status & f & $\%$ & Valid \% & Cumulative \% \\
\hline Not Yet Certified & 108 & 51.2 & 51.2 & 51.2 \\
\hline Certified & 103 & 48.8 & 48.8 & 100.0 \\
\hline
\end{tabular}

$\mathrm{N}=211$

Table 3 shows that $90 \%$ of the teachers have participated in pedagogical trainings held either by regional, provincial or national committee; whereas, the rest (10\%) have not been trained yet.

Table 3. Teacher Training Participation

\begin{tabular}{|c|c|c|c|c|}
\hline Involvement & f & \% & Valid \% & Cumulative \% \\
\hline No & 21 & 10.0 & 10.0 & 10.0 \\
\hline Yes & 190 & 90.0 & 90.0 & 100.0 \\
\hline
\end{tabular}

$\mathrm{N}=211$

As shown in Table 3, the trainings they attended vary in length of time as seen in Table 4. Most of them $(40.3 \%$ or 85 respondents) have participated in at least 3 (three)-day training, $38.9 \%$ (77 respondents) have attended 4-or 6-day training and the rest (49 respondents or $58.7 \%$ ) have attended more than 6 days but less than a month as depicted in Table 4 below.

Table 4. Cumulative Length of Training (in Days)

\begin{tabular}{|c|c|c|c|c|}
\hline Length in Days & f & \% & Valid \% & Cumulative \% \\
\hline $0-3$ & 85 & 40.3 & 40.3 & 40.3 \\
\hline $4-6$ & 82 & 38.9 & 38.9 & 79.1 \\
\hline $7-10$ & 37 & 17.5 & 17.5 & 96.7 \\
\hline $11-14$ & 3 & 1.4 & 1.4 & 98.1 \\
\hline
\end{tabular}




\begin{tabular}{|c|c|c|c|c|}
\hline $15-30$ & 3 & 1.4 & 1.4 & 99.5 \\
\hline$>30$ & 1 & .5 & .5 & 100.0 \\
\hline
\end{tabular}

$\mathrm{N}=211$

According to the respondents, the trainers are all scholars with various education backgrounds, ranging from those holding a Bachelor of Arts up to a Doctorate degree. In practice, most training $(50.2 \%)$ are handled by those with the Bachelor of Arts degree, $25.6 \%$ by a Master's degree, $10.9 \%$ by a Doctorate degree, and the rest by a team of trainers. For clarity, see Table 5.

Table 5. Trainer Education Background

\begin{tabular}{|c|c|c|c|c|}
\hline Education & f & $\%$ & Valid \% & Cumulative \% \\
\hline S-1 & 106 & 50.2 & 50.2 & 50.2 \\
\hline S-2 & 54 & 25.6 & 25.6 & 75.8 \\
\hline S-3 & 23 & 10.9 & 10.9 & 86.7 \\
\hline S-1 and S-2 & 10 & 4.7 & 4.7 & 91.5 \\
\hline S-2 and S-3 & 15 & 7.1 & 7.1 & 98.6 \\
\hline S-1, S-2, and S-3 & 3 & 1.4 & 1.4 & 100.0 \\
\hline
\end{tabular}

$\mathrm{N}=211$; S-1: graduate; S-2: Master's; S-3: Doctorate degrees

Further, the respondents stated that most of the trainers $(32.5 \%)$ were competently experienced. Moreover, $64 \%$ of them were all provincially or nationally trained by the government, and $3.7 \%$ were at the university level, as shown in Table 6.

Table 6. Trainer Attributes

\begin{tabular}{|c|c|c|c|c|c|}
\hline \multicolumn{2}{|c|}{ Experienced } & \multicolumn{2}{c|}{ National/Provincial Level } & \multicolumn{2}{c|}{ University-level } \\
\hline $\mathbf{f}$ & $\%$ & $\mathrm{f}$ & $\%$ & $\mathrm{f}$ & $\%$ \\
\hline 68 & 32.3 & 134 & 64 & 78 & 3.7 \\
\hline
\end{tabular}

$\mathrm{N}=211$

As experienced by the respondents, the trainers implemented various training techniques which include a synergy of lecturing and the use of power point at the most, lecturing and group simulation, question and answer, pre-group discussion followed by feedback, lecturing and video watching, and all techniques are always ended by peer teaching, either individually or in group. However, $25 \%$ of the respondents (around 12 teachers) claim that the technique used is lecturing with no PowerPoint and followed by question and answer as depicted in Table 7.

Table 7. Training Techniques Used by Trainers

\begin{tabular}{|c|c|}
\hline Techniques & f \\
\hline A & 12 \\
\hline B & 32 \\
\hline C & 115 \\
\hline D & 140 \\
\hline E & 66 \\
\hline F & 103 \\
\hline G & 38 \\
\hline H & 76 \\
\hline I & 50 \\
\hline J & 65 \\
\hline N = 211 & \\
\hline
\end{tabular}

The result of statistical analysis in Table 8 reveals that the training materials cover the latest issues of Standards of Content of Curriculum 2013, recommended student-centered instructional models, technology-based instructional media, authentic assessment, classroom action research. There are also topics on classroom management, materials for remedy and enrichment but there is no material for writing for publication on scientific journals.

Table 8. Training Materials Trained
\begin{tabular}{|c|c|}
\hline Materials Trained & f \\
\hline A & 121 \\
\hline B & 132 \\
\hline C & 95 \\
\hline D & 18 \\
\hline
\end{tabular}




\begin{tabular}{|c|c|}
\hline E & 54 \\
\hline F & 69 \\
\hline G & 80 \\
\hline H & 28 \\
\hline I & 65 \\
\hline J & 42 \\
\hline
\end{tabular}

$\mathrm{N}=211$

In the trainings, most respondents opine that they are actively involved in all activities on site such as paying attention to lecturing, doing worksheets in pairs or group, participating in group and class discussion, simulating what has been trained during trainings. Nonetheless, only a few have attempted to implement what they have learned in the trainings into classroom practice. The data is presented in Table 9 below.

Table 9. Participants' Activities

\begin{tabular}{|c|c|c|}
\hline Activities & $\mathbf{f}$ & $\mathbf{\%}$ \\
\hline A & 65 & \\
\hline B & 104 & \\
\hline C & 19 & \\
\hline D & 75 & \\
\hline E & 24 & \\
\hline
\end{tabular}

$\mathrm{N}=211$

Anyhow, according to the respondents, it is indispensable to attend professional trainings to increase their professional competence. Table 10 shows that $97 \%$ of them agree to the provision of the trainings, and only $3 \%$ disagree.

\begin{tabular}{|c|c|c|c|c|}
\multicolumn{5}{c}{ Table 10. Usefulness of the Trainings } \\
\hline Usefulness & $\mathbf{f}$ & $\%$ & Valid \% & Cumulative \% \\
\hline No & 6 & .3 & 2.8 & 2.8 \\
\hline Yes & 205 & 9.7 & 97.2 & 100.0 \\
\hline
\end{tabular}

$$
\mathrm{N}=211
$$

Regarding the adequacy of teaching needs, $53 \%$ of the respondents think that the trainings attended suit their needs. However, $47 \%$ of them still think that the trainings do not suit their needs as seen in Table 11.

Table 11. Adequacy of Teaching Needs

\begin{tabular}{|c|c|c|c|c|}
\hline Adequacy & f & $\%$ & Valid \% & Cumulative \% \\
\hline No & 99 & 4.7 & 46.9 & 46.9 \\
\hline Yes & 112 & 5.3 & 53.1 & 100.0 \\
\hline
\end{tabular}

$\mathrm{N}=211$

Based on the description in Table 12, almost all the respondents (96\%) agree that the materials presented in the trainings are of good quality. Only a small number of them $(4 \%)$ disagree with the quality of the materials.

\begin{tabular}{|c|c|c|c|c|}
\hline \multicolumn{1}{l}{ Table 12. Quality Materials } \\
\hline Quality Materials & f & $\%$ & Valid \% & Cumulative \% \\
\hline No & 9 & .4 & 4.3 & 4.3 \\
\hline Yes & 202 & 9.6 & 95.7 & 100.0 \\
\hline
\end{tabular}

$95 \%$ of the respondents commented that the materials are innovative. $5 \%$ stated that they are not innovative at all as shown in Table 13 below.

Table 13. Innovative Materials

\begin{tabular}{|c|c|c|c|c|}
\hline Innovative Materials & $\mathbf{f}$ & $\%$ & Valid Percent & Cumulative Percent \\
\hline .00 & 10 & .5 & 4.7 & 4.7 \\
\hline 1.00 & 201 & 9.5 & 95.3 & 100.0 \\
\hline
\end{tabular}

It is verified that $60 \%$ of the respondents stated that the presentation of theory and practice is only effective during trainings as shown in Table 14. 
Table 14. Onsite Theory and Practice

\begin{tabular}{|c|c|c|c|c|}
\hline Onsite Trainings & $\mathbf{f}$ & $\%$ & Valid \% & Cumulative \% \\
\hline No & 84 & 4.0 & 39.8 & 39.8 \\
\hline Yes & 127 & 6.0 & 60.2 & 100.0 \\
\hline
\end{tabular}

All in all, all trainings for professional development provide benefits as well as drawbacks for trainees. According to the respondents, on one hand, the trainings attended are beneficial for them to increase their competence. The competent, experienced and creative trainers provide them with indepth materials of Curriculum 2013, innovative instructional model, and assessment. The training focuses more on practices than theories. Trainee are given more opportunity to practice and actively engaged in classroom activities. These can increase their pedagogical and professional competence. On the other hand, there are some drawbacks such as the imbalanced portion of theory and practice, insufficient time for accomplishing the tasks in the worksheets, incompetent trainers in the regency, the use of too much English in delivering the materials, superficial explanation of the content, limited time of training, and inadequate time of asking questions.

Further, according to the respondents, when joining any professional training, they had such expectations. The following are what they expect from attending the training:

1. To elevate their personal, pedagogical as well as professional knowledge,

2. To keep up with up to date instructional models of learning and the latest issues of education

3. To develop good lesson plans including classroom-based assessment process, developing classroom action research

4. To have various continuous trainings by local district/regency

5. To be more competent in classroom management and classroom-based problem solving,

6. To promote critical thinking skills

7. to improve technology-based teaching and learning

8. to have sustainable mentoring

9. to collect various learning materials

10. to obtain applicable research-based trainings

11. to develop teacher-made instructional materials

12. to have sufficient time of trainings

13. to focus on one particular subject matter

14. to have intensive monitoring, evaluation and supervision

15. to have pre tutorial of the training materials

16. to have more practices than theories

17. to become future peer tutors.

Teachers are in favor of trainings that consist of a small portion of theory presentation and more practice in schools under an expert guidance. They respondents prefer to such trainings due to the following reasons:

1. More practices will provide them with deeper comprehension

2. Practices and mentoring will be more advantageous in managing class practices at schools

3. Practices should be in line with grounded theories

4. It will assist teachers to conduct classroom action research

5. Sustainable trainings will promote professionalism

6. The trainings will provide long-term effect on their pedagogical competences.

Teachers expected that trainings will give them empowerment. The following are the expectation they have for their empowerment:

1. To be competent in conducting classroom action research;

2. To collaborate theories, practices, and evaluation with a ratio of $25 \%, 50 \%$, and $25 \%$;

3. To facilitate teachers to be more academically and pedagogically independent;

4. To be able to handle blended learning in class;

5. To be provided with a systematic training starting from something general to something specific;

6. To conduct peer teaching and real teaching;

7. To be exposed to innovative ways of teaching;

8. To conduct benchmarking particularly to schools with technology facilities;

9. To be trained by competent and professional trainers.

Teachers asserted their needs of the use of technology to support teaching and learning. Table 15 displays the data that $95 \%$ of the respondents (201 teachers) opine that the use of the Internet is required during the instructional process, and only $5 \%$ think it is not vital. 
Table 15. The Need of Internet Technology Use in Class

\begin{tabular}{|c|c|c|c|c|}
\hline Importance of ICT Use in Classrooms & $\mathbf{f}$ & $\%$ & Valid \% & Cumulative \% \\
\hline No & 10 & 5 & 4.7 & 4.7 \\
\hline Yes & 201 & 9.5 & 95.3 & 100.0 \\
\hline
\end{tabular}

$\mathrm{N}=211$

As shown in Table 16, $62.6 \%$ of the respondents stated that they have developed ICT-based EFL learning, and $37.4 \%$ have not.

Table 16. Developing ICT-based EFL learning

\begin{tabular}{|c|c|c|c|c|}
\hline ICT Use & f & $\%$ & Valid \% & Cumulative \% \\
\hline .No & 79 & 3.7 & 37.4 & 37.4 \\
\hline Yes & 132 & 6.3 & 62.6 & 100.0 \\
\hline
\end{tabular}

According to them, the use of ICT in class advocates merits in EFL learning as expressed by $98.48 \%$ of the respondents. Only $1.52 \%$ of them do not acknowledge this. The data is shown in Table 17.

Table 17. Merits of Using ICT for EFL Learning

\begin{tabular}{|c|c|c|c|c|}
\hline ICT Use & $\mathbf{f}$ & $\%$ & Valid \% & Cumulative \% \\
\hline No & 2 & 1.52 & 1.52 & 1.52 \\
\hline Yes & 130 & 98.48 & 98.48 & 100.0 \\
\hline
\end{tabular}

The advantages of ICT uses are, among others, widening horizon of knowledge, making it easier for teachers to ask students to browse references for their assignments, making students more interested in learning, finding more various instructional materials, promoting more active learning, being exposed to more innovative issues on EFL, being efficient in instructional process, being more practical in teaching, enriching instructional media in the form of technology, helping teachers to score students' work, facilitating fast communication, encouraging concentration, making students more interested in learning English, visualizing facts, enhancing audio-visual method, disseminating knowledge and skills and inspiring.

About skills, 139 respondents $(66 \%)$ exclaim that they have attempted to implement what they acquired in the course of trainings; whereas, $34 \%$ have not applied the skills gained from previous trainings as seen in Table 18.

Table 18. Implementing the Skills acquired from Previous Trainings

\begin{tabular}{|c|c|c|c|c|}
\hline Application & f & $\%$ & Valid \% & Cumulative \% \\
\hline No & 72 & 3.4 & 34.1 & 34.1 \\
\hline Yes & 139 & 6.6 & 65.9 & 100.0 \\
\hline
\end{tabular}

However, most of the respondents $(80 \%)$ agree to disseminate the skills they have acquired in the trainings to fellow teachers through group discussion, inviting school clusters, in-house training at regional teacher forum, sharing training materials to peer teachers, and sharing experiences to others virtually. The data is shown in Table 19.

Table 19. Disseminating the Skills Gained from Previous Training

\begin{tabular}{|c|c|c|c|c|}
\hline Dissemination & f & $\%$ & Valid \% & Cumulative \% \\
\hline No & 42 & 2.0 & 19.9 & 19.9 \\
\hline Yes & 169 & 8.0 & 80.1 & 100.0 \\
\hline
\end{tabular}

Concerning classroom action research, Table 20 shows that $54 \%$ of the respondents never conduct a classroom action research, and only $46 \%$ have conducted CAR. In their opinion, conducting CAR is essential for teachers due to several reasons. CAR enables teachers to measure students' achievement, to provide more knowledge in research, to overcome classroom problems through empirical procedures, to encourage career promotion, develop professionalism, measure the success of instructional process, improving instructional process via comprehensive study, examine suitable instructional methods and media for students, discover relevant treatment for students, conduct selfreflection to investigate instructional weaknesses, improve oneself, strengthen concepts, identify students' competences.

Table 20. Conducting Classroom Action Research (CAR)

\begin{tabular}{|c|c|c|c|c|}
\hline Doing CAR & f & $\%$ & Valid \% & Cumulative \% \\
\hline No & 113 & 5.4 & 53.6 & 53.6 \\
\hline Yes & 98 & 4.6 & 46.4 & 100.0 \\
\hline
\end{tabular}


Table 21 shows that $68 \%$ of teachers still need to learn some topics related to CAR, such as formulating research problem, review of theory, research methodology including instrumentation, data analysis, and report writing.

Table 21. Need to Learn Further about CAR

\begin{tabular}{|c|c|c|c|c|}
\hline Response & f & $\%$ & Valid \% & Cumulative \% \\
\hline No & 17 & .8 & 8.1 & 8.1 \\
\hline Yes & 143 & 6.8 & 67.8 & 75.8 \\
\hline No response & 51 & 2.4 & 24.2 & 100.0 \\
\hline
\end{tabular}

Concerning the vital role of CAR in professional development, most of the respondents $(80 \%)$ have no experience in writing scientific articles for a seminar. Only $20 \%$ have written articles. The data is presented in Table 22 below.

Table 22 Experiences in Writing Scientific Articles for Seminar.

Table 22. Experiences in Writing Scientific Articles for Seminar

\begin{tabular}{|c|c|c|c|c|}
\hline Experience & f & $\%$ & Valid \% & Cumulative \% \\
\hline No & 168 & 8.0 & 79.6 & 79.6 \\
\hline Yes & 43 & 2.0 & 20.4 & 100.0 \\
\hline
\end{tabular}

$\mathrm{N}=211$

It is shown in table $23,60 \%$ of the respondents have expressed that writing scientific articles for publication is necessary to promote their professionalism. Whereas, $25 \%$ of them think it is unnecessary, and the rest did not comment at all.

Table 23. Importance of Writing Articles for publications

\begin{tabular}{|c|c|c|c|c|}
\hline Importance & f & \% & Valid \% & Cumulative \% \\
\hline No & 53 & 2.5 & 25.1 & 25.1 \\
\hline Yes & 127 & 6.0 & 60.2 & 85.3 \\
\hline No response & 31 & 1.5 & 14.7 & 100.0 \\
\hline
\end{tabular}

$\mathrm{N}=211$

The data in table 24 below has reinforced the urgency to enhance teachers' professionalism. As evidence, $86 \%$ of the respondents have never written research-based articles for journal publication, and only $20 \%$ have done it.

Table 24. Writing CAR Articles and Journal Publication

\begin{tabular}{|c|c|c|c|c|}
\hline Experience & $\mathbf{f}$ & $\%$ & Valid \% & Cumulative \% \\
\hline No & 181 & 8.6 & 85.8 & 85.8 \\
\hline Yes & 30 & 1.4 & 14.2 & 100.0 \\
\hline
\end{tabular}

$\mathrm{N}=211$

For the last variable, as shown in Table $25,54.8 \%$ of the respondents are challenged to write scientific articles for publication, and the rest, $45.2 \%$ are not.

Table 25. Challenges in Writing Article Publications

\begin{tabular}{|c|c|c|c|c|}
\hline Challenges & f & $\%$ & Valid \% & Cumulative \% \\
\hline No & 34 & 1.6 & 54.8 & 54.8 \\
\hline Yes & 28 & 1.3 & 45.2 & 100.0 \\
\hline
\end{tabular}

Based on the findings presented in Tables1 to Table 25, some insight can be drawn based on theoretical insights and previous studies.

\section{DISCUSSION}

Based on the findings, it is obvious that teachers give two types of responses concerning teacher training: adequate and inadequate. The former covers several aspects such as teaching experience, activities in the training, materials and teaching techniques used in the training, etc. In the context of teaching experience, teachers have cumulative different length of teaching experiences. However, the majority of the teachers $(64.9 \%)$ have less than 10 year teaching experiences and a few $(8.5 \%)$ have more than 10-year teaching experience. This different experience may reflect levels of their knowledge which may refer to subject matters, models of teaching, instructional media, instructional materials, classroom management, etc. It may also reflect that most of the teachers are probably young (their ages are around 30-35 years) who have rigorous energy and motivation to develop their 
competence. They have the potential to be effective teachers. Sanders and Rivers' study (1996:4-5) discovered that in the first seven years of teaching, teachers' effectiveness increased, but inclined to be flat by tenth year. Harris \& Sass (2011) also found out that the largest gain of elementary middle school teacher productivity increases within five years of teaching experience. In other words, less than 10 years of teaching experience can be said as a golden period to develop effective teaching and productivity. According to Rice (2010), experience, gained over time, can enhance the knowledge, skills, and productivity of teachers. Effective teachers are those who have the verbal ability, content knowledge, education coursework, teacher certification and teacher experience (Darling-Hammond, 2000: 2-7).

In relation to the training, teachers provide positive responses. Most of the teachers $(90 \%)$ have participated in the pedagogical training held either by regional, provincial or national committees. The teachers' involvement in training is also supported by the fact that $97 \%$ of teachers think that having training is crucial for their professional development. It indicates that they are aware of the importance of teacher training for professional development. According to (Davidson, et al., 2012; Mizell, 2010; the Indonesian Government Act, 2005 \& 2007; \& Guskey, 2003), teachers as professionals are compulsory to keep on upgrading themselves through the so-called "Continues Professional Development (CPD) Programs", one of which is teacher training. Their involvement in the training will give a positive impact on both teachers' credentials and students' achievements (Guskey, 2003). Lumpe, Czerniak, Haney, \& Beltyukova (2012) confirm that teachers who are actively involved in a long-term professional development program tend to have significant gains in their teaching self-efficacy. Therefore, teachers, as the most important factor contributing to students' achievement (Goldhaber, 2004), need a great deal of attention.

Second, they also considered that the materials presented in the training are of good quality and innovative, and the training techniques implemented by the trainers varied. It seems that the contents and techniques used in the training are designed to keep up with the advancement of technology and current issues such as the development of curriculum and models of teaching. Various types of activities also enable teachers to be actively involved in the training to construct their knowledge. However, this good preparation might be less effective if the training is conducted in limited time and it has become the concern of the trainees.

The second type of response concerns with the inadequacy of several aspects of the training. For example, they think that not all teachers' trainings conducted are effective in the sense that the trainings has not fully provided positive impact on the instructional process in class as well as on their professional growth. Although trainings have been provided for teachers, they are commonly conducted in a short period. The survey shows that most of the teachers (40.3\% or 85 respondents) have participated in at least 3 (three)-day training, $38.9 \%$ (77 respondents) 4-or 6-day training and the rest (49 respondents or $58.7 \%$ ) more than 6 days but less than a month. None of the teachers joins training in sufficient time.

Limited duration for the trainings can be one of the factors contributing to ineffective training. Ineffective training, according to Schostak, Davis, Hanson, Schostak, Brown, Driscoll, Starke, \& Jenkins (2010), does not include both" learning" and being "fit to practice", meaning that CPD scaffold teachers to know the "why" and the "how". Further, Schostak et al. (2010) state that effectiveness is facilitated when professionals are able to determine their own learning needs through reflection within the totality of their practice.

The drawbacks that might appear concerning the limitation of time dedicated for the training. Firstly, trainers work hard to present all materials to fulfill the targets within a limited time period. Accordingly, they may conduct more on one-way interaction (teacher-centered) than two-way interaction (teacher-student centered). The coverage of theories and practices in the training may also be imbalanced. Second, teachers may not be able to grasp a lot of materials although they are well prepared. Usually, teachers are required to read, understand, and do a lot of work on curriculum, instructional models of learning, developing good lesson plans including classroom-based assessment process, developing classroom action research, etc. To Lumpe, Czerniak, Haney, \& Beltyukova (2012), it is difficult for teachers to obtain significant gains in their teaching self-efficacy when the trainings only take days.

Other important issues are related to the use of technology in the training, sustainability of the training, and writing articles for publication. Using technology is now required to facilitate teaching and learning. Technology helps teachers not only prepare their materials but also present or deliver messages. Students, at the same time, also get benefits from the use of technology in classroom. It makes it easier for them to understand the concept and it also makes learning more enjoyable. A study by Lee \& Erdogan (2007) indicates that students who were taught with technology have shown significant improvement not only in the development of their positive attitudes but also in creativity skills. 
The sustainability of the training is then important so that teachers can continuously upgrade themselves. The sustainability can be maintained in many ways as long as teachers keep reading, thinking, and doing something useful following the training. As presented in the survey, the knowledge and skills they obtain from the trainings are effective during the trainings only. They are easily forgotten after teachers go back to their teaching routines. One important attempt to maintain sustainability is by doing classroom action research and writing articles for publication. They can benefit from their teaching practices and students' learning to conduct research and disseminate the results through seminars/conferences and journals. According to Davidson et al. (2012) and the Indonesian laws through The Teachers and Lecturers Act No.14/2005 $(2005,2007)$ and the Ministry Education and Culture (2012), teachers can upgrade themselves periodically through (1) promoting Personally-Initiated Learning (PIL); (2) attending Organized Professional Development (OPD); (3) publishing Innovative Work (IW); (4) upgrading into Qualified Professional Teachers (QPT; and (5) managing More Advance Roles (MAR).

\section{CONCLUSIONS AND RECOMMENDATIONS}

Based on the data analysis, some conclusion can be drawn. Firstly, teachers acquire more receptive theories than direct practices resulting in insufficient internalization of the training materials. Secondly, modeling provided by the trainers is less than the trainees have expected so they do not really know how to elaborate the practices. Thirdly, all of them are of the opinion that the training duration is limited, therefore, some parts of the materials have not been comprehensively discussed and not all materials are covered. Finally, the intensive follow-up activities are insufficient. Henceforth, the objective stated in the Government Laws number 14 year 2005 and number 16 year 2007 about Teacher Standards of Qualifications and Competences is not optimally achieved.

As the recommendation, "Reflective Training", a model of training that refines past training models is necessary to be conducted since this training model focuses on providing facilitation to teachers, starting from training to on-the-site assistance based on contextual identification and analysis of the issues in the school context as well as reviewing strategies appropriate to the problem locally. In addition, this training model will empower trained teachers with competences in planning, implementing what they have planned, observing, evaluating and finally doing a reflection. In short, the impact of the process of reflective training is to foster the belief that the trainees are able to design a lesson, and to solve the problems in their classroom. The professional development may take the form of in-service and on-service trainings.

\section{REFERENCES}

----------. (2005). Undang-Undang Guru dan Dosen Nomor 14. Jakarta: Ministry of Education and Culture.

(2007). Standar Kualifikasi dan Kompetensi Guru dan Dosen. Jakarta: Ministry of Education and Culture.

Amalia, N. (2017).Pre-Service Teachers' Self Reflection on their Pedagogical

Competences upon Joining the SM-3T Program.Unpublished Thesis. Malang: Universitas Negeri Malang.

Darling-Hammond, L. (2000). Teacher Quality and Student Achievement: A Review of State Policy Evidence. Educational Policy Analysis Archive, 8(1). Downloaded from http://olam.ed.asu.edu/ epaa/v8n1

Davidson, G., Dunlop, F., Soriano, D.H., Kennedy, L., \& Phillips, T. (2012).Going Forward: Continuing Professional Development for English Language Teachers in the UK.British Council.

Gall, M.D., Gall, J.P. \& Borg, W.R. (2007).Educational Research. Eight Edition. New York: Pearson.

Gnanaguru, S. A. \& Kumar, S. (2007). Attitude of under normal and overachievers towards teaching profession and their home environment. Journal of All India Association for Educational Research, Vol. 19 (3): 36-37.

Goldhaber, D. E. (2004). Indicators of teacher quality. ERIC Clearinghouse on Urban Education New York NY. Downloaded from http://www.ericdigests.org/2004-1/quality.htm

Guskey, T.R. (2003). What makes professional development effective? Phi Delta Kappan, 84 (10), 748750.

Harris, D \& Sass, T. (2011). Teacher Training, Teacher Quality and Student Achievement. Journal of Public Economics, 95 (7) 798-812

Kemendikbud. (2012). PedomanPengelolaanPengembanganKeprofesianBerkelanjutan. Jakarta: BPSSDMPK \& PMP PusatPengembanganProfesiPendidik. 
Suharyadi, Gunadi H. Sulistyo \& Sri Rachmajanti

Lee, M.K \& Erdogan, I. (2007). The Effect of Science-Technology-Society Teaching on Students' Attitudes toward Science and Certain Aspects of Creativity. International Journal of Science Education. 29(11), 1315-1327

Lumpe, A., Czerniak, C., Haney, J., \& Beltyukova, S. (2012). Beliefs about Teaching Science:The Relationship between Elementary Teachers' Participation in Professional Development and Student Achievement. International Journal ofScience Education,34(2), 153-166.

Mizell, H. (2010). Why Professional Development Matters. Oxford: Learning Forward.

Rice, J.K. (2010). The Impact of Teacher Experience Examining the Evidence and Policy Implications. Downloaded from http://www.urban.org.

Sanders, W.L. \& Rivers, J.C. (1996). Cumulative and Residual Effects of Teachers on Future Student Academic Achievement. Knoxville: University of Tennessee Value-Added Research and Assessment Center

Schostak, J., Davis, M., Hanson, J., Schostak, J., Brown, T., Driscoll, P., Starke, I. and Jenkins, N. (2010). Effectiveness of Continuing Professional Development' Project: A Summary of Findings. Medical Teacher, 32(7), 586-592.

Utami, I.G.A.L.P., Saukah, A., Cahyono, B.Y., \&Rachmajanti, S.R. (2017). Levels of Involvement in the Teachers' Continuous Professional development: The Degree of Professional Enthusiasm. The Journal ofAsia TEFL, 14 (2), 336-345. 